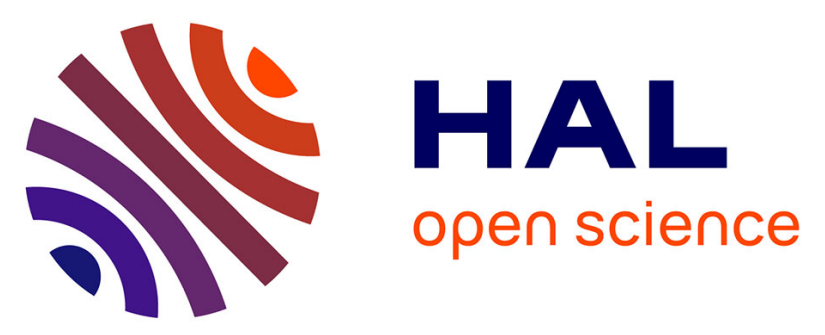

\title{
Low fouling conditions in dead-end filtration: Evidence for a critical filtered volume and interpretation using critical osmotic pressure
}

\author{
Yolaine Bessiere, Nouhad Abidine, Patrice Bacchin
}

\section{To cite this version:}

Yolaine Bessiere, Nouhad Abidine, Patrice Bacchin. Low fouling conditions in dead-end filtration: Evidence for a critical filtered volume and interpretation using critical osmotic pressure. Journal of Membrane Science, 2005, 264 (1-2), pp.37-47. 10.1016/j.memsci.2005.04.018 . hal-00201135

\section{HAL Id: hal-00201135 \\ https://hal.science/hal-00201135}

Submitted on 24 Dec 2007

HAL is a multi-disciplinary open access archive for the deposit and dissemination of scientific research documents, whether they are published or not. The documents may come from teaching and research institutions in France or abroad, or from public or private research centers.
L'archive ouverte pluridisciplinaire HAL, est destinée au dépôt et à la diffusion de documents scientifiques de niveau recherche, publiés ou non, émanant des établissements d'enseignement et de recherche français ou étrangers, des laboratoires publics ou privés. 


\title{
LOW FOULING CONDITIONS IN DEAD-END FILTRATION: \\ EVIDENCE FOR A CRITICAL FILTERED VOLUME AND INTERPRETATION \\ USING CRITICAL OSMOTIC PRESSURE
}

\author{
Y. Bessiere ${ }^{1}$, N. Abidine $^{2}$, P. Bacchin ${ }^{1, *}$ \\ ${ }^{1}$ Laboratoire de Génie Chimique, Université Paul Sabatier, 118 route de Narbonne, 31062 Toulouse cedex, France \\ 2 Aquasource, 20 avenue Didier Daurat, BP 4050, Toulouse Cedex 4, France \\ *Corresponding author: bacchin@chimie.ups-tlse.fr, Tel: (33) 561558163
}

\begin{abstract}
This paper presents experiments showing the existence of a critical filtered volume $(C F V)$ when operating colloid dead-end filtration. The $C F V$ is here defined as the filtered volume below which there is no irreversible (with respect to a break in the filtration) fouling on the membrane surface: it has thus the same meaning as cross-flow critical flux but applied to a dead-end process. The existence of the $C F V$ is demonstrated when filtering stable latex or clay suspensions in constant-flux filtration experiments with alternating rinses: in contradiction to the current view, an irreversible deposit is not formed as soon as dead-end filtration begins. This critical filtered volume is shown to be dependent on the suspension stability and to be fully linked to the permeate flux: for permeate fluxes of 80 and $1101 \mathrm{~h}^{-1} \mathrm{~m}^{-2}$ the $C F V$ is respectively 82 and $651 \mathrm{~m}^{-2}$ for latex particles. Analyses of results are made by depicting the transition between concentration polarisation and deposit formation considering a critical osmotic pressure which appears to be a characteristic of the fouling potential of a suspension. The results are discussed in the light of how this concept could lead to an interesting way to control and develop a strategy to operate filtration in dead-end mode.
\end{abstract}

Keywords: critical conditions, osmotic pressure, fouling test, deposit formation, dead-end filtration 


\section{Introduction}

The rapid development of separation systems using membranes made it possible to use pressure-driven processes in a large range of industrial applications. Thus, ultrafiltration is now the principal step in potable water production. For such a low added-value product, costs have to be minimized. Therefore, membrane manufacturers started to develop dead-end units which proved to lead to energy efficient systems [1].

For both cross-flow and dead-end mode, fouling represents a real limitation. Indeed, this phenomenon, attributed as much to adsorption as to gel formation or particle deposition, leads to an unavoidable rise in production costs by increasing both the energy consumption (to maintain a constant flux) and the cleaning frequencies (backwashes or chemical cleaning). Thus, understanding fouling phenomena and developing ways to anticipate and control them rapidly proved to be essential for the development of water treatment technologies and other applications.

The concept of critical flux has been defined for cross-flow filtration as the flux below which a decline of permeability with time does not occur $[2,3]$. The critical flux and its consequences on how filtration should be operated have been experimentally studied for various suspensions [4], membranes [5] and operating conditions [6]. These critical conditions

are linked to the idea of sustainable development for a process by defining operating conditions for which fouling is minimised, thus needing little energy to remove it.

Since membrane manufacturers have managed to decrease membrane prices, it became possible to explore low-flux operation with large membrane surfaces leading to the same or to lower global production costs by saving energy. To optimize operating conditions leading to the best compromise between cost and productivity, research has focused on the development of procedures allowing the determination of running parameters leading to low-fouling operations. In this way, part of the project MemEau coordinated by the Aquasource company 
(Toulouse, France) focuses on the determination of low fouling conditions in dead-end filtration for water treatment applications.

It is reasonable to assume that an extensive use of membranes under critical conditions (as opposed to intensive use with high pressures or high fluxes associated to heavy fouling) can be an essential key toward sustainable operations.

The focus of the work presented here is to investigate the possibility of avoiding or limiting irreversible fouling in dead-end filtration by using rinses, which do not lead to high energy losses unlike backwashes. This implies that the limit between the different fouling mechanisms has to be clearly identified.

\section{Background}

Accumulation of colloidal matter on the membrane surface is inherent to the separation

process; it can be limited but never totally avoided. However, accumulation can lead to different fouling mechanisms (pore blocking or blinding, adsorption, cake formation, concentration polarisation [7]) having different consequences on the permeate flux and different degrees of reversibility. Here, we consider the case where fouling is mainly controlled by surface mechanisms and not by internal fouling. Even if surface accumulation has most often been studied as a global cake, some authors $[8,9]$ found that the colloidal deposit can be considered as a combination of a loose reversible layer (concentration polarization) and an irreversible packed structure (gel or deposit layer).

\subsection{Concentration polarization}

During filtration, particles can remain in a dispersed phase forming a concentrated polarized layer. They provide an additional opposition to transfer via the contribution of the osmotic pressure; when associating this contribution with Darcy's law, the flux $(J)$ can then be 
described as a function of transmembrane pressure $(\Delta P)$, osmotic pressure at the interface between membrane and suspension $\left(\Pi_{m}\right)$, fluid viscosity $(\mu)$ and resistance of the membrane $\left(R_{m}\right)$

$$
J=\frac{\Delta P-\Pi_{m}}{\mu \cdot R_{m}}
$$

Eq. 1

Osmotic pressure, which is well known as the limiting phenomenon during reverse osmosis of salt solution, always has a significant effect on colloidal dispersion ultrafiltration [10]: 100 $\mathrm{nm}$ particles can exhibit osmotic pressure around 0.2 bars when concentrated as experimentally shown [11]. Authors working on physical aspects of concentrated colloidal dispersions [12] show that a critical osmotic pressure exists, $\Pi_{\text {crit }}$, (for a critical volume fraction) above which there is aggregation between dispersed particles. During separation, the critical osmotic pressure can be reached on the membrane leading to the formation of layers of irreversibly aggregated particles.

\subsection{Irreversible fouling layer formation}

The formation of colloidal irreversible fouling layers is the consequence of the fact that concentration polarisation reaches its maximum capacity.

At the membrane surface this can mean:

- A critical volume of matter leading to a critical osmotic pressure from a thermodynamic point of view.

- A critical force balance implying that dispersive repulsion forces between solutes or particles are counter-balanced by convective drag forces (summing the drag forces of all the accumulated particles [8]) from a mechanistic point of view.

The idea of a critical concentration is well known since 1968, when it was introduced by Michaels into the gel model [13] and it is often used in developing transient models for 
molecular filtration [14]; but it is not a concept traditionally used for colloids which are usually considered as particles, to be described by a cake filtration approach implying formation of a deposit as soon as matter accumulates at the surface. However, it is important, at this point, to accept that even with colloid particles there can be a critical concentration as shown by Jonsson et al. in 1996 [12] with a thermodynamic approach and by Petsev et al. in 1993 with a critical force balance [15]; above this critical point, irreversible multilayers of aggregated colloidal particles can then form on the membrane surface, something like a gel or a deposit layer [16]. Such a mechanism then causes additional resistance $\left(R_{c}\right)$ to the filtration which is irreversible. Logically, during its formation there is always a concentrated polarised layer at the surface at its maximum concentration providing the critical osmotic pressure leading to the following expression for the permeate flux:

$$
J=\frac{\Delta P-\Pi_{c r i t}}{\mu \cdot\left(R_{m}+R_{c}\right)}
$$

Eq. 2

It is important to control the development of these irreversible fouling layers and to know what filtration operating conditions lead to its formation.

\subsection{Critical fouling conditions}

Critical fouling can be defined as the process operating conditions leading to the formation of irreversible multilayer fouling on the membrane. The physical meaning of the term critical is used here to relate the irreversible phase transition between a dispersed (reversible concentration polarization) and a condensed phase (irreversible multilayer deposit). When running a filtration process, several parameters determine the occurrence of the phase transition at the membrane surface, these critical parameters being different when operating in cross flow or in dead end mode. 
$\bullet$ Cross flow

In cross-flow filtration, a steady state critical flux can be found below which no irreversible fouling occurs $[2,3]$. However, this critical flux is dependent on another operating condition: the cross-flow velocity. Critical conditions can then be defined with the pair of the following operating parameters: permeate flux and cross-flow velocity. For a given cross-flow velocity, a critical permeate flux can be defined $[17,18]$ or, for a given permeate flux a critical cross flow velocity exists [17]. So, a critical ratio of permeate flux over the wall shear stress [18] or a critical Peclet number [16] has been theoretically and experimentally introduced to account for this double effect. The critical pair of operating conditions can then be defined as the product of the permeate flux, $J$, and the mass boundary layer thickness, $\delta$, (function of the cross flow velocity): $(J . \delta)_{\text {crit }}$.

\section{- Dead-end}

Since dead-end filtration implies a continual transient state, a steady critical flux concept as deduced from cross flow filtration cannot be directly applied. Furthermore, it is commonly accepted that for particles, a deposit forms as soon as filtration begin (cake filtration approach), but, Petsev et al. [12] have theoretically shown that when filtering charged colloidal particles in the dead-end mode at a given moment (called the critical time) the coagulation of particles at the membrane surface occurs: the hydrodynamic force acting on the first layer of particles at the membrane overcome the repulsive interaction between particles caused by their charges. A model developed to evaluate reversibility in dead-end operations [8] shows that the formation of a compact irreversible layer occurs for a critical value of the pair "permeate flux and accumulated mass" (accumulated mass being proportional to the filtered volume or to a critical time [12] -for constant flux operation-). For a given filtered volume, a critical permeate flux can be defined or for a given permeate flux there exists a 
critical filtered volume. The product of the deposited mass, $m$, and the permeate flux was found to be critical: $(J . m)_{c r i t}$. These results led to the optimisation of cleaning procedures (backwashes or flushes) improving the efficiency of filtration operations.

The following paper proposes a procedure allowing the determination of critical fouling conditions for deposit formation in dead-end processes through the measurement of a critical filtered volume for a given permeate flux. The experiments are carried out on suspensions of latex and of clays. The analyse through fouling resistance leads to the definition of an associated parameter for the description of the transition by way of the critical osmotic pressure which links the degree of fouling reversibility to process operating conditions.

\section{Materials and methods}

\subsection{Feed suspensions}

Two types of feed suspensions were used: a suspension with well known particle properties (latex suspension), as a basis for a better understanding of the phenomena occurring during dead-end filtration, and a clay suspension to come closer to actual water treatment worries.

\section{- Latex}

A latex suspension made with monodisperse spherical PVC particles was used and diluted with $10^{-3} \mathrm{M} \mathrm{KCl}$ in distilled water to reach $0.02 \mathrm{wt} \%$ (corresponding to $0.0144 \%$ in volume). In these conditions the particles are dispersed: the critical coagulation concentration was found in a previous study [17] to be larger than $0.1 \mathrm{M}$ of $\mathrm{KCl}$. This concentration corresponded to a turbidity of 160 NTU. Particle size distribution was measured with a laser granulometer Zêtasizer 4 (Malvern, Worcestershire, UK). The average latex diameter was 120 $\mathrm{nm}$ for the ionic strength used. The $\mathrm{pH}$ of the solution was between 6 and 7 corresponding to a 
zeta potential of $-71 \mathrm{mV}$ with an associated error of $2 \mathrm{mV}$ (after correction with the relationship of O’Brien et al. 1978) [11].

- Clay

The clay suspension was made of platelet-shaped bentonite particles, (the larger dimension is about a hundred times greater than the thickness). The primary clay solution was obtained by dispersing $30 \mathrm{~g}$ per litre of osmosis-purified water (Millipore) followed by four repeated sedimentations (each lasting 4 hours) to produce stable suspensions. The resulting concentration was about $17 \mathrm{~g} / \mathrm{L}$ containing micron sized colloidal particles with a mean hydrodynamic diameter centred on $700 \mathrm{~nm}$ [19]. This suspension was then diluted with $10^{-3}$ $\mathrm{M} \mathrm{KCl}$ in distilled water (well below the critical coagulation concentration found at $10^{-2} \mathrm{M}$ in $\mathrm{KCl}[19])$ to obtain a $0.02 \mathrm{~g} / \mathrm{L}$ concentration, corresponding to $6.5 \mathrm{NTU}$. This suspension without any buffering then typically displayed a $\mathrm{pH}$ between 6 and 7 corresponding to a corrected zeta potential of around $-41 \mathrm{mV}[20]$.

\subsection{Filtration rig}

The experiments were carried out with a bench-scale unit (Fig. 1) using inside-out hollow fibre made of cellulose acetate (Aquasource, Toulouse, France) having a low molecular weight cut-off implying no internal fouling or pore blocking with previously presented feed suspensions.

To avoid contamination of the clean water (used to measure initial permeability), the ultrafiltration module was fed separately with osmosis-purified water (clean water tank) or with the suspension studied (suspension tank).

A volumetric pump ensures a constant flux during the dead-end filtration experiment. Pressure transducers (0-5 bar, Keller) were used to monitor the inlet and outlet pressure, as 
well as the permeate pressure. The permeate flow was measured using an electromagnetic flowmeter (COPA XE Bailey Fischer \& Porter). A temperature transducer was situated on the permeate pipe. All parameters were recorded every $30 \mathrm{~s}$ via a computer. Operating conditions and membrane characteristics are summarized in Table 1.

\subsection{Processing}

Formation of an irreversible layer was identified using a succession of filtration periods and discontinuous rinses. The aim of the rinsing step was to remove the reversible accumulated layer. The residual resistance remaining after the rinse was then assumed to be the resistance of the deposit formed during the previous filtration period.

\section{- filtration}

Filtrations were carried out with a constant given flux. Firstly, the flux was adjusted using RO-purified water (clean water tank): the initial permeability of the clean module $\left(L p_{0}\right)$ at the reference temperature of $20^{\circ} \mathrm{C}$ can then be checked.

$$
L p_{0}\left(20^{\circ} \mathrm{C}\right)=\frac{J}{\Delta P_{0}} \cdot \frac{\mu(T)}{\mu\left(20^{\circ} \mathrm{C}\right)}
$$

where $\mu$ is the viscosity at the experimental temperature $(T)$ or at the reference temperature $\left(20^{\circ} \mathrm{C}\right)$ and the transmembrane pressure $\left(\Delta P_{0}\right)$ is taken as the average of the inlet and outlet pressures minus the permeate pressure. Then, the feed was switched to the suspension tank indicating the beginning of the filtration test. After filtration for a given time (corresponding to a filtered volume $V f$ ) a rinse was performed.

\section{- Rinsing step}

Rinses were run by opening the valve at the outlet of the module, with a chosen frequency defined by the specific volume in $1 \mathrm{~m}^{-2}$ filtered between each rinsing step $(V f)$. As critical 
fouling conditions are defined as the first deposition of colloids on the membrane [21], rinses have to be run in well defined conditions (Table 2). In order to avoid erosion of the deposit by shearing, rinses were run at very low flow and a large volume was circulated in the module, with a single passage, to ensure the removal of dispersed particles in a polarization concentration.

The whole experiment corresponded to a total volume produced of $2501 \mathrm{~m}^{-2}$ leading, in the worst case, to losses in raw water through rinsing steps smaller than 7\%. By performing rinses after filtering progressively increasing volumes the idea is to detect the first irreversible gel or deposit layer at the membrane (section 4.3).

\section{Experimental results}

Reversibility of fouling was measured by a set of experiments where rinses were processed after the filtration of different volumes of suspension as described in the previous section. Filtration/rinse cycles are first presented in terms of variation of relative permeability along the cycle (4.1) used to deduce a residual resistance after the rinsing steps (4.2). The evolution of this residual resistance with the filtered volume shows the presence of a critical filtered volume (4.3).

\subsection{Evolution of permeability along filtration/rinse cycles}

In order to show the appearance of a possible drift in permeability, the evolution of relative permeabilities, defined as the ratio between instantaneous $(L p)$ and initial permeability $\left(L p_{0}\right)$, was plotted versus filtered volume all along the filtration / rinse experiments. 
- Latex

Experiments of latex filtration were performed for two different fluxes: 80 and $1101 \mathrm{~h}^{-1} \mathrm{~m}^{-2}$ and for each flux with at least three different filtered volumes per cycle. Fig. 2 presents the influence of the filtered volume between rinsing steps on the evolution of the relative permeability for three volumes between 35 and $841 \mathrm{~m}^{-2}$ for the largest flux.

When the filtered volume per cycle $V f$ was only $35 \mathrm{l} \mathrm{m}^{-2}$, the relative permeability was recovered after each rinsing step, indicating that no irreversible fouling had occurred during the filtration period. When the filtered volume was increased up to 74 and $841 \mathrm{~m}^{-2}$, a drift in the specific permeability was observed leading to a loss of about 10 and $20 \%$ respectively after each rinse. This is indicative that irreversible fouling (possibly due to particle deposition) was able to occur within the filtration period.

\section{- Clay suspension}

The same protocol was used to study reversibility on the clay suspension, using imposed fluxes of 50 and $801 \mathrm{~h}^{-1} \mathrm{~m}^{-2}$. Fig. 3 shows the result when the flux was $801 \mathrm{~h}^{-1} \mathrm{~m}^{-2}$ and the filtered volume between rinses increased from 35 up to $911 \mathrm{~m}^{-2}$.

The same general observations as for latex can be made for the clay suspension results: a drift in permeability rapidly occurred when increasing the volume filtered between rinsing steps going from $2 \%$ to $21 \%$ lost per cycle for filtered volume $V f$ of 35 and $911 \mathrm{~m}^{-2}$, respectively.

\subsection{Residual resistance versus filtered volume}

In order to analyse these results, a residual resistance, $R_{\text {res, }}$ is defined as the difference between the resistance remaining at the beginning of a new cycle $\left(\mathrm{R}_{\mathrm{ci}}\right)_{n}$ and the resistance at the beginning of the previous cycle $\left(\mathrm{R}_{\mathrm{ci}}\right)_{n-1}$. For a series of filtration/rinse cycles, the residual resistance is taken as the averaged value of that calculated over the two first cycles, the 
residual resistance being almost constant along cycles. This residual resistance is plotted in Fig. 4 and 5 for latex and bentonite respectively versus the filtered volume between each rinsing step and for the different permeate fluxes. The standard deviation of the residual resistance around the averaged value for the two first cycles is plotted in this graph as error bars.

In Fig. 4, the curves present a similar trend for the different fluxes studied and two periods can be easily identified:

- the first part, up to 60 and $851 \mathrm{~m}^{-2}$ for 110 and $801 \mathrm{~h}^{-1} \mathrm{~m}^{-2}$ respectively, during which the residual resistance is still negligible,

- the second part, where a dramatic increase in the residual resistance occurs.

The results obtained during filtration of the bentonite suspension (Fig. 5) present the same trends, however the discontinuity is less abrupt and the limit between fouling and non-fouling conditions is more fuzzy. Actually, the increase observed in the residual resistance with the filtered volume is about $50 \%$ slower than the increase rate observed for the latex suspension.

\subsection{Critical filtered volume (CFV)}

The critical filtered volume $(C F V)$ is determined by taking the intersection of the tangents of the two parts of the curve as shown in Fig. 5 which represents the variation of the residual resistance (remaining after a rinse) as a function of the volume filtered in the previous filtration cycle. The $C F V$ then corresponds to the limit between fouling and non-fouling conditions. Fig. 6 and Table 3 summarize the critical filtered volumes obtained with the experiments presented previously. In this way, it can be shown (fig. 6) that the critical accumulated volume is dependent both on the flux and on the kind of suspension studied. Thus, previous research on critical deposition of colloid suspensions showed that critical conditions (such as critical flux in cross flow) are fully linked to the suspension stability: 
critical flux is lower for an increase in ionic strength (and thus reduced repulsive interactions between particles) in the same suspension [8]. It seems clear here that deposits occur for a smaller filtered volume (for a given flux) for bentonite suspensions: at $801 \mathrm{~h}^{-1} \mathrm{~m}^{-2}$ the critical filtered volume is around $551 \mathrm{~m}^{-2}$ for clays and $821 \mathrm{~m}^{-2}$ for latex. Furthermore, the clay is ten times more dilute than the latex suspension (see section 3.1); the normalization using the mass bulk concentration $\left(C_{b}\right)$, as shown in Table 3 , leads to a more discriminating parameter: the critical accumulated mass $\left(C F V^{*} C_{b}\right)$.

The experimental results obtained confirmed the existence of a suitable parameter highlighted by Harmant and Aimar (1996) to describe critical fouling conditions in dead-end operations: $(J \cdot C F V)_{c r i t}$ or $\left(J \cdot C F V \cdot C_{b}\right)_{c r i t}$ when using the critical accumulated mass (second and last column in Table 3 respectively). Indeed this parameter seems to be suitable to characterise the membrane / suspension combination as it was found to be roughly constant for a given suspension and equal to $4600 \pm 2.5 \%$ for the clay and $6850 \pm 6.1 \%$ for the latex (Table 3 ). This parameter can be considered as a criterion for the stability of the suspension: the higher its value the more stable the dispersion (see later on section 6.2.).

The criticality between non-fouling and fouling is pronounced when filtering latex dispersions but less marked for clays. This behaviour could be explained by the idea of a distribution in critical fouling conditions for large colloids, induced by the difference of shape and the wide size distribution of the bentonite particles. The concept can then slip from critical fouling conditions with the existence of no fouling conditions towards sustainable fouling conditions where fouling can occur but is minimised to reduce its impact on the operation. 


\section{Interpretation of critical filtration conditions in terms of critical osmotic pressure}

The experimental results presented in the previous section are now analysed in terms of osmotic pressure and hydraulic deposit resistance, phenomena which are respectively related to concentration polarisation and deposition mechanisms (for background see sections 2.1 and 2.2). In order to shed light on the transition between concentration polarization and cake formation, the first part of the filtration results (where the cake does not form) is explained in terms of osmotic pressure (5.1.). A critical osmotic pressure is then determined from filtration/rinse experiments (5.2.) and later used to characterise the transition between polarisation and deposition during filtration (5.3.).

\subsection{Method for interpretation of experimental results}

Filtration experiments are interpreted by considering consecutive fouling steps:

Step A. In the first part of a filtration run, before any possible cake formation, transfer resistance is due to concentration polarization; the flux is limited by the osmotic pressure at the membrane $\Pi_{m}$, corresponding to eq. 1 for a fully retentive membrane.

Step B. When concentration at the membrane increases sufficiently to provoke the destabilization of particles i.e. when osmotic pressure at the membrane, $\Pi_{m}$, reaches a critical value, $\Pi_{\text {crit }}$, a deposit forms on the membrane providing an additional irreversible resistance $\left(R_{c}\right)$. If a deposit is currently forming, the concentration of polarised particles then remains constant and is associated with a critical osmotic pressure $\left(\Pi_{\text {crit }}\right)$ : the maximum osmotic pressure reachable in the polarisation concentration. The flux is then given by eq. 2 . 
Step C. Just after a rinse, assuming that the rinse volume is sufficient to entirely remove the polarised particles, the osmotic pressure is reduced to the osmotic pressure of the bulk (here ignored). However, a residual resistance, $R_{\text {res }}$ can remain.

Even if, from a physical point of view, the flux is described by different equations (eq. 1 or 2), from a mathematical point of view it is possible to consider the same filtration law accounting for an "osmotic pressure like" term [22]:

$$
J=\frac{\Delta P-\Pi_{m}}{\mu \cdot R_{m}}
$$

which has a different meaning according to the filtration step :

step A $-\Pi_{m}$ is the osmotic pressure

step B $-\Pi_{m}$ is the combination of the critical osmotic pressure and a cake resistance:

$$
\Pi_{m}=\Pi_{c r i t}+J \cdot \mu \cdot R_{c}
$$

Eq. 5

step $\mathrm{C}-\Pi_{m}$ is relative to the residual resistance persisting after the rinsing step

$$
\Pi_{m}=J \cdot \mu \cdot R_{\text {res }}
$$

Eq. 6

In eq. 4 , it should be noted that $\Pi_{m}$ represents an osmotic pressure (thermodynamically reversible) when $\Pi_{m}$ is lower than $\Pi_{\text {crit }}$ (step A) whereas when $\Pi_{m}$ is above $\Pi_{c r i t}$ (step B) it is relative to a compressive pressure in a solid phase: the "over-osmotic pressure", $\Pi_{m}-\Pi_{c r i t}$ represents the pressure drop in the cake layer. In order to reflect these different characters, $\Pi_{m}$ can generally be considered as the solid pressure [23] at the membrane.

If plotting the solid pressure, $\Pi_{m}$ defined as the difference between the instantaneous transmembrane pressure $(\Delta P)$ and the initial transmembrane pressure $\left(\Delta P_{0}\right)$ relative to the 
clean membrane and the operating flux, as a function of filtered volume along filtration steps $\mathrm{A}, \mathrm{B}$ and $\mathrm{C}$ (Fig. 7), the residual hydraulic resistance of cycle $\mathrm{n}+1,\left(R_{r e s}\right)_{n+1}$, appears to be linked to the residual solid pressure (eq. 6) which can then be written as a difference of transmembrane pressures:

$$
\left(R_{r e s}\right)_{n+1}=\frac{\left(\Delta P_{i}\right)_{n+1}-\left(\Delta P_{i}\right)_{n}}{\mu \cdot J}
$$

where $\left(\Delta P_{i}\right)_{n}$ and $\left(\Delta P_{i}\right)_{n+1}$ represent the initial transmembrane pressure of cycle $n$ and $n+1$ respectively.

The critical osmotic pressure can be easily deduced from figure 7 as being the solid pressure removed during the rinsing step. It is then possible to determine the value of $\Pi_{\text {crit }}$ for the cycle $n$ as the difference of transmembrane pressure just before and after the rinsing step:

$$
\left(\Pi_{c r i t}\right)_{n}=\left(\Delta P_{f}\right)_{n}-\left(\Delta P_{i}\right)_{n+1}
$$

where $\left(\Delta P_{f}\right)_{n}$ refers to the final transmembrane pressure of cycle $n$.

or more strictly

$$
\left(\Pi_{c r i t}\right)_{n}=\left[\frac{\left(\Delta P_{f}\right)_{n}}{\left(\mu \cdot J_{f}\right)_{n}}-\frac{\left(\Delta P_{i}\right)_{n+1}}{\left(\mu \cdot J_{i}\right)_{n+1}}\right] \cdot\left(\mu \cdot J_{f}\right)_{n}
$$

when taking into account the slight variation in temperature and flux during the experiment.

\subsection{Determination of critical osmotic pressure}

One can now easily determine the value of $\Pi_{\text {crit }}$ corresponding to each cycle from the initial and final trans-membrane pressure of a filtration cycle. The values found for each cycle (Table 4) are almost constant and make it possible to determine, by numerical optimisation on all cycles, a single value of $\Pi_{\text {crit }}$ describing the whole filtration/rinse cycles experiment.

The averaged $\Pi_{\text {crit }}$ values determined for the different volumes and fluxes are reported in Tables 5 and 6 for latex and clay filtrations, respectively. 
For a given suspension, values of critical osmotic pressure determined for different operating conditions (filtered volume and applied permeate flux) appear to be almost the same except when the filtered volume is close to the critical filtered volume resulting in low residual resistance (double star in Tables 5 and 6). If we do not take into consideration the values corresponding to low residual resistances (lower than $5 \%$ of the clean membrane resistance), several observations can be made on the critical osmotic pressure results: whereas the critical filtered volume was found dependent on the permeate flux, the critical osmotic pressure is here independent of operating conditions. Then, the value of critical osmotic pressure $\Pi_{\text {crit }}$ found for the clay suspension is lower than that experimentally determined for latex suspensions highlighting that this parameter is only relative to the suspension / membrane set (discussed in section 6.2.).

\subsection{Filtration interpretation with critical osmotic pressure}

Furthermore, such an approach allows dissociation of these different fouling mechanisms during the filtration step. When assuming that residual resistance after rinsing corresponds to the deposit formed during the previous filtration period (absence of erosion during the rinsing step), it is possible to depict the different contributions of fouling in terms of cake resistance and osmotic pressure. Table 7 presents equations used for the first cycle and then generalized to a filtration cycle n: these contributions are described below (concentration polarization at the membrane surface) and above (growth of the deposit) $\Pi_{c r i t}$ using the light and dark parts respectively. The same colour code will be used in Fig. 8 to describe the increase in concentration of the dispersed phase and the growth of the deposit.

It should be noted that the value of the critical osmotic pressure then allows the variation of the pressure to be described along the filtration/rinse cycle. Indeed, the equations presented in Table 7 make it possible to split the global resistance into (reversible) osmotic pressure and 
(irreversible) cake formation contributions, plotted versus filtered volume in fig. 8: during the first part of the filtration the particles reaching the membrane are accumulated in a dispersed phase (A); they cause an additional resistance to transfer through their osmotic pressure $\left(\Pi_{m}\right)$ increasing with the concentration i.e. with the filtered volume. When the volume fraction of the dispersed phase reaches its maximum value, a deposit starts forming (B) whereas the osmotic contribution remains constant at its maximum reachable value $\left(\Pi_{c r i t}\right)$. Then, rinsing allows depolarization of the accumulation (C). When filtration carries on as before, the increase in concentration of the dispersed phase appears at the deposit / suspension interface (step A').

\section{Discussion}

Here, we discuss the consequences of the critical filtered volume and its associated critical osmotic pressure on how to interpret filtration data (6.1), to characterise the stability of a suspension in regard to its filtration (6.2), and to operate dead-end filtration (6.3).

\subsection{Critical osmotic pressure and fouling lag}

The determination of $\Pi_{\text {crit }}$ can be considered as a new way of characterising fouling, being complementary to the classical fouling index. The fouling index or fouling potential are

relative to the hydraulic resistance of a deposit during the cake filtration phase (the intensity of the fouling) whereas the critical filtered volume and its associated critical osmotic pressure are relative to a fouling lag during which fouling is reversible then being indicative of the potential of the membrane/suspension system to resist the formation of irreversible fouling (a kind of no-fouling potential). These characterisations of fouling are then complementary as schematically presented in Fig. 9 by plotting the residual resistance versus filtered volume. The slope of the residual resistance over filtered volume after the critical value can then be 
considered as relative to irreversible fouling and is directly linked to the specific resistance of the irreversible deposit $(\alpha)$ whereas the intercept point is linked to the fouling lag.

The determination of the fouling lag and its associated critical osmotic pressure can then give information on the ability of the membrane/suspension system to stand up to the formation of irreversible fouling (cake or gel) which will be seen in the next section as linked to the stability properties of the suspension. It should be noted that this fouling lag could be the cause for the existence of a critical filtration time which has been experimentally determined during sludge filtration in submerged membrane bioreactors $[24,25]$. When working below the critical flux in such processes, the concentration at the membrane surface can continue to grow, leading after a critical filtered volume (or a critical time), to the formation of a cake resistance and then to a sudden permeability loss.

\subsection{Critical osmotic pressure and suspension stability characterisation}

It has been clearly shown in section 4 that when different suspensions (latex and clay particles) are filtered with a given permeate flux, the experimentally determined critical filtered volumes are different. The critical osmotic pressure, $\Pi_{c r i t}$, used to interpret these experiments (section 5) is then different: around $6 \mathrm{kPa}$ for the clay suspension and $40 \mathrm{kPa}$ for the latex suspension.

Such results are in good agreement with theories accounting for surface interactions in transport phenomena [13] since the clay suspension is less stable than the latex suspension: this is confirmed by measurements of zeta potential presented in the Materials section which is lower for clays $(-41 \mathrm{mV})$ than for latex suspension $(-71 \mathrm{mV})$. These high charges on latex particles lead to large repulsive interaction that can explain the high value of the critical osmotic pressure: the pressure needed to irreversibly aggregate the latex dispersion is high. 
Critical osmotic pressure is then found to be relative to the suspension stability with regard to filtration. The determination of $\Pi_{c r i t}$ could be an interesting tool to classify the fouling characteristics of the suspension in relation to the membrane used.

\subsection{Consequences on operating dead-end filtration processes}

The determination of critical conditions by filtration/rinse experiments leads to essential keys to run optimized dead-end filtrations: it is observed that, for a defined suspension / membrane set, a working zone can be defined where it is possible to avoid - or at least to greatly limit irreversible fouling. This working zone can be defined by the operating conditions: the permeate flux, $J$, and the filtered volume per filtration cycle, $C F V$ (fig. 10). Below the dashed curves in this figure (corresponding to a critical value of the product $J^{*} C F V$ ) fouling is totally reversible and it can be possible to work with cycles of filtration and rinses. Above this dashed line, irreversible fouling appears which then requires back flushing to recover permeability. It is important to note that the critical filtered volume decreases when increasing the permeate flux: increasing the permeate flux reduces the possibility to work without irreversible fouling.

For a given working flux, it is possible to reduce the global production cost: indeed the right choice of a "cleaning" frequency corresponding to a filtered volume slightly below the critical value allows the removal of additional resistance by actions requiring low energy (rinsing phases). Such a way to run the process can be seen as sustainable since fouling is reduced to its minimum (above these conditions, an irreversible deposit forms on the membrane surface implying the need for expensive mechanical or even chemical actions).

It is clear that the border between no fouling and fouling conditions becomes less sharp as suspensions become increasingly disperse (in composition and size) as already discussed in section 4.2. However, a similar trend with the appearance of significant fouling above a 
critical filtered volume has also been observed during dead-end filtration of natural organic matter using constant pressure operation [26]. Below this critical filtered volume, the reduction of flux due to mass accumulation is instantaneously reversible showing the possibility of the application of this concept to the "real world" of membrane processes. Actually, even when considering a complex fluid, such as natural surface water, likely to add more fouling phenomena (compared to model suspensions) such as adsorption or pore blocking, one can expect critical conditions to exist.

\section{Conclusion}

The work presented in this paper contributes to the development of sustainable dead-end filtration operations: indeed, it has been clearly shown experimentally that periodic rinses can be sufficient to avoid a drift in permeability when they are carried out before the formation of the irreversible layer (Fig. 10). This is an important point to investigate for the development of dead-end units as it leads to savings of energy compared with the use of regular backwashes.

The precise determination of the limits between the different fouling mechanisms is then essential to run filtration operations as it can provide indications about the operating parameters suitable to work in the reversible fouling zone. Such a limit is defined by a critical osmotic pressure (which is indicative of a liquid/solid transition at the membrane surface); its experimental determination could be a useful tool for process optimisation. This parameter was found to be almost independent of operating conditions and so suitable for the description of the suspension: the critical osmotic pressure is determined at 40 and $6 \mathrm{KPa}$ respectively for latex and clay particles. The associated critical filtered volume is shown to be closely related

to the permeate flux: for example for latex particles, permeate fluxes of 80 and $1101 \mathrm{~h}^{-1} \mathrm{~m}^{-2}$ result in $C F V^{\prime}$ 's of 82 and $651 \mathrm{~m}^{-2}$ respectively. An interesting perspective is to use this tool 
on a real suspension, such as natural surface water where the mechanisms of fouling are more complex on account of the diversity of compounds in terms of shape, size and charge.

\section{Acknowledgments:}

We are grateful to the French technological network RITEAU for supporting the MemEau project "Water-clarification processes based on ultra-filtration for a rational control of quality, energy, discharge and costs" and the Aquasource company (Toulouse, France) for participating in and coordinating the project. 


\section{References}

[1] K. Parameshwaran, A.G. Fane, B.D. Cho and K.J. Kim, Analysis of microfiltration performance with constant flux processing of secondary effluent. Wat. Res., 35 (2001) 43494358.

[2] R.W. Field, D.Wu, J.A. Howell and B.B. Gupta, Critical flux concept for microfiltration fouling. J. Membr. Sci., 100 (1995) 259-272.

[3] P. Bacchin, P. Aimar and V. Sanchez, Model for colloidal fouling of membranes. AIChE journal, 41 (1995) 368-376.

[4] D.Y. Kwon and S. Vigneswaran, Influence of particle size and surface charge on critical flux of crossflow microfiltration. Water Sci. Tehnol. 38 (1998) 481-488

[5] I.H. Huisman, E. Vellenga, G. Trägårdh and C. Trägårdh, The influence of the membrane zeta potential on the critical flux for cross-flow microfiltration of particle suspensions. J. Membr. Sci. 156 (1999) 153-158.

[6] S.S. Madaeni, The effect of operating conditions on critical flux in membrane filtration of latexes. Process Safety Environ. Protect. 75 B4 (1997) 266-269

[7] G. Belfort, R.H. Davis and A.L. Zydney, The behaviour of suspensions and macromolecular solutions in cross flow microfiltration. J. Membr. Sci. 96 (1994) 1-58.

[8] P. Harmant and P. Aimar, Coagulation of colloids retained by porous wall. AIChE journal 42 (1996) 3523-3532.

[9] V.Chen, A.G. Fane, S. Maedeni and I.G. Wenten, Particle deposition during membrane filration of colloids: transition between concentration polarization and cake formation. J. Membr. Sci. 125 (1999) 109-122. 
[10] W.R. Bowen and P.M. Williams, Obtaining the osmotic pressure of electrostatically stabilised colloidal dispersions from frontal ultrafiltration experiments. J. Colloid Interf. Sci. $233(2001) 159-163$.

[11] B. Espinasse, Approche théorique et expérimentale de la filtration tangentielle de colloïdes : flux critique et colmatage. PhD thesis, Université Paul Sabatier, Toulouse, 2003. [12] A-S. Jönsson and B. Jönsson, Ultrafiltration of colloidal dispersion - A theoretical model for the concentration polarization phenomena. J. Colloid Interf. Sci. 180 (1996) 504-518.

[13] A.S. Michaels, New separation technique for the CPI. Chem. Eng. Prog. 64 (1968) 3143.

[14] S.K. Zaidi, S.K. Karode, D. Kirpalani and A. Kumar, A new method for identifying osmotically limited and gel layer controlled pressure independent flux in ultrafiltration. Can. J. Chem. Eng. 82 (2004) 343-348.

[15] D.N.Petsev, V.M Starov and I.B. Ivanov, Concentrated dispersions of charged colloidal particles: sedimentation, ultrafiltration and diffusion. Colloids and Surf. A, 81 (1993) 65-81. [16] P. Bacchin, D. Si-Hassen, V. Starov, M.J. Clifton and P. Aimar, A unifying model for concentration polarization, gel-layer formation and particle deposition in cross-flow membrane filtration of colloidal suspensions. Chemical Engineering Science 57 (2002) 77-91. [17] B. Espinasse, P. Bacchin and P. Aimar, On an experimental method to measure critical flux in ultrafiltration. Desalination 146 (2002) 91-96.

[18] G. Gesan-Guiziou, E. Boyaval and G. Daufin, Critical stability conditions in cross flow microfiltration of skimmed milk: transition to irreversible deposition. J. Membr. Sci. 158 (1999) 211-222.

[19] P. Bacchin, P. Aimar, V. Sanchez, Influence of surface interaction on transfer during colloid ultrafiltration. J. Membr. Sci., 115 (1996) 49-63. 
[20] C. Causserand, K. Joven, P. Aimar and M. Meireles, Modification of clay cake permeability by adsorption of protein. J. Membr. Sci., 137 (1997) 31-44.

[21] J.A. Howell, Sub-critical flux operation of microfiltration. J. Membr. Sci., 107 (1995) $165-171$

[22] M. Elimelech and S. Bhattacharjee, A novel approach for modelling concentration polarization in crossflow membrane filtration based on the equivalence of osmotic pressure model and filtration theory. J. Membr. Sci. 145 (1998) 223-241.

[23] P. Bacchin, M. Meireles and P. Aimar, Modelling of filtration: from the polarized layer to deposit formation and compaction. Desalination 145 (2002) 139-146.

[24] B.D. Cho and A.G. Fane, Fouling transients in nominally sub-critical flux operation of a membrane bioreactor. J. Membr. Sci. 209 (2002) 391-403.

[25] S. Ognier, C. Wisniewski and A. Grasmick, Membrane bioreactor fouling in sub-critical filtration conditions: a local critical flux concept. J. Membr. Sci., 229 (2004) 171-177. [26] Y. Bessiere, P. Bacchin and B. Jefferson, Dead-end filtration of natural organic matter: experimental evidence of critical conditions, to be published in Desalination, FCF'04. 
Table 1: Hollow fibre properties and operating conditions.

\begin{tabular}{llr}
\hline Membrane working length & $(\mathrm{m})$ & 1.12 \\
Fibre internal diameter & $(\mathrm{mm})$ & 0.94 \\
Number of fibres & $(-)$ & 21 \\
Total membrane area & $\left(\mathrm{m}^{2}\right)$ & 0.07 \\
Molecular cut-off & $(\mathrm{kDa})$ & 80 \\
Initial permeability @ $20^{\circ} \mathrm{C}$ & $\left(1 \mathrm{~h}^{-1} \mathrm{~m}^{-2} \mathrm{bar}^{-1}\right)$ & 250 \\
\hline Permeate flux & $\left(1 \mathrm{~h} \mathrm{~h}^{-1} \mathrm{~m}^{-2}\right)$ & from 50 to 140 \\
\hline
\end{tabular}


Table 2: rinse characteristics.

\begin{tabular}{llr}
\hline Feed flow & $\left(1 \mathrm{~h}^{-1}\right)$ & 5.6 \\
Internal passage area & $\left(\mathrm{m}^{2}\right)$ & $1.46 \cdot 10^{-5}$ \\
Internal volume & $\left(\mathrm{m}^{3}\right)$ & $1.63 \cdot 10^{-5}$ \\
Velocity & $\left(\mathrm{m} \mathrm{s}^{-1}\right)$ & 0.105 \\
Shear rate & $(\mathrm{Pa})$ & 0.9 \\
Reynolds & $(-)$ & $10 *$ internal volume \\
Volume of the rinse & $(-)$ & \\
\hline
\end{tabular}


Table 3: critical conditions in terms of a) filtered volume and b) accumulated mass for the two suspensions studied.

\begin{tabular}{|c|c|c|c|c|c|}
\cline { 3 - 6 } \multicolumn{2}{c|}{} & \multicolumn{2}{c|}{ a)Accumulated filtered volume } & \multicolumn{2}{c|}{ b)Accumulated mass } \\
\cline { 3 - 6 } \multicolumn{2}{c|}{} & $\begin{array}{c}C F V \\
\left(1 \mathrm{~m}^{-2}\right)\end{array}$ & $\begin{array}{c}J^{*} C F V \\
\left(\mathrm{l}^{2} \mathrm{~h}^{-1} \mathrm{~m}^{-4}\right)\end{array}$ & $\begin{array}{c}C F V^{*} C_{b} \\
\left(\mathrm{~g} \mathrm{~m}^{-2}\right)\end{array}$ & $\begin{array}{c}J^{*} C F V^{*} C_{b} \\
\left(1 \mathrm{~g} \mathrm{~h}^{-1} \mathrm{~m}^{-4}\right)\end{array}$ \\
\hline \multirow{2}{*}{ Clay } & $J=50$ & 85 & 4250 & 1.8 & 90 \\
\cline { 2 - 6 } & $J=80$ & 55 & 4400 & 1.1 & 88 \\
\hline \multirow{2}{*}{ Latex } & $J=80$ & 82 & 6560 & 16.4 & 1312 \\
\cline { 2 - 6 } & $J=110$ & 65 & 7150 & 13.0 & 1430 \\
\hline
\end{tabular}


Table 4: Determination of critical osmotic pressure, $\Pi_{\text {crit }}$ and its associated residual resistance, $R_{\text {res }}$, from an experiment: latex $-J=1101 \mathrm{~h}^{-1} \mathrm{~m}^{-2}-V f=841 \mathrm{~m}^{-2}$ between rinses (fig. 2 )

\begin{tabular}{|c|c|c|c|c|c|c|c|c|}
\hline \multirow{2}{*}{ Cycle number } & \multicolumn{2}{|c|}{0} & \multicolumn{2}{|c|}{1} & \multicolumn{2}{|c|}{2} & \multicolumn{2}{|c|}{3} \\
\hline & $\mathrm{i}$ & $\mathrm{f}$ & $\mathrm{i}$ & $\mathrm{f}$ & $\mathrm{i}$ & $\mathrm{f}$ & $\mathrm{i}$ & f \\
\hline $\mathrm{KPa}$ & 45.2 & 97.9 & 61.6 & 122.8 & 84.5 & 143.2 & 102.2 & - \\
\hline$\left(\Pi_{c r i t}\right)_{n} \quad \mathrm{KPa}$ & & & & & & & & \\
\hline$R_{\text {res }} \quad \mathrm{m}^{-1}$ & & & & & & & & \\
\hline
\end{tabular}


Table 5: critical osmotic pressure, $\Pi_{c r i t}$, deduced from filtration/rinse cycles experiments for the latex suspension - ${ }^{*}$ no irreversibility observed $-{ }^{* *}$ weak irreversibility observed.

\begin{tabular}{|c|cccc|ccccc|}
\cline { 2 - 9 } \multicolumn{1}{c|}{} & \multicolumn{4}{c|}{$J=801 \mathrm{~h}^{-1} \mathrm{~m}^{-2}$} & \multicolumn{5}{c|}{$J=1101 \mathrm{~h}^{-1} \mathrm{~m}^{-2}$} \\
\hline Filtered volume $\left(1 \mathrm{~m}^{-2}\right)$ & 34 & 70 & 85 & 103 & 35 & 49 & 62 & 75 & 84 \\
\hline$\Pi_{\text {crit }}(\mathrm{kPa})$ & $-^{*}$ & $-^{*}$ & $27^{* *}$ & 40 & $-^{*}$ & $-^{*}$ & $34^{* *}$ & 40.3 & 40 \\
\hline
\end{tabular}


Table 6: critical osmotic pressure, $\Pi_{\text {crit }}$, deduced from filtration/rinse cycles experiments for the clay suspension - ${ }^{*}$ no irreversibility observed $-{ }^{* *}$ weak irreversibility observed.

\begin{tabular}{|c|cccc|cccc|}
\cline { 2 - 8 } \multicolumn{1}{c|}{ bentonite } & \multicolumn{4}{|c|}{$J=501 \mathrm{~h} \mathrm{~h}^{-1} \mathrm{~m}^{-2}$} & \multicolumn{4}{c|}{$J=801 \mathrm{~h}^{-1} \mathrm{~m}^{-2}$} \\
\hline Filtered volume $\left(1 \mathrm{~m}^{-2}\right)$ & 50 & 91 & 120 & 140 & 34 & 50 & 70 & 91 \\
\hline$\Pi_{\text {crit }}(\mathrm{kPa})$ & $-^{*}$ & 5.9 & 5.9 & 6.0 & $3.5^{* *}$ & 4.5 & 5.6 & 6.0 \\
\hline
\end{tabular}


Table 7: calculation of the contribution of osmotic pressure and cake in the global resistance.

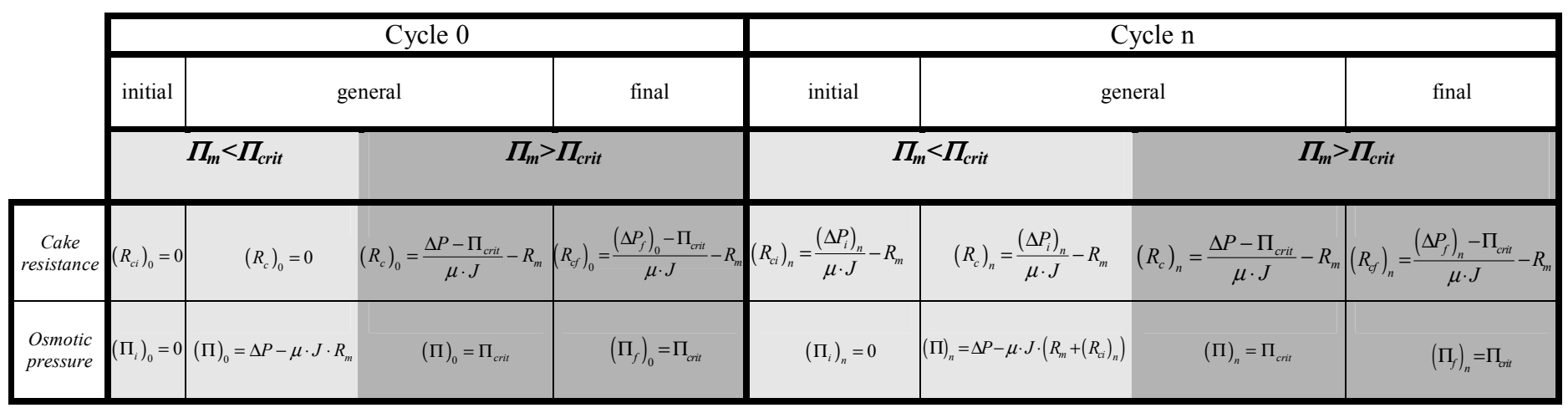




\section{Figure Captions}

Fig.1. Schematic of the filtration bench scale unit.

Fig.2. Evolution of relative permeability $L p / L p_{0}$ during filtration/rinse cycles for different filtered volumes during the filtration step $V f$ - latex suspension $0.2 \mathrm{~g} \mathrm{l}^{-1}-J=110 \mathrm{~h} \mathrm{~h}^{-1} \mathrm{~m}^{-2}-$ $L p_{0}=2551 \mathrm{~h}^{-1} \mathrm{~m}^{-2} \mathrm{bar}^{-1} @ 20^{\circ} \mathrm{C}$.

Fig.3. Evolution of relative permeability $L p / L p_{0}$ during filtration/rinse cycles for different filtered volumes during the filtration step $V f$ - clay suspension $0.02 \mathrm{~g} \mathrm{l}^{-1}-J=801 \mathrm{~h}^{-1} \mathrm{~m}^{-2}-$ $L p_{0}=2551 \mathrm{~h}^{-1} \mathrm{~m}^{-2} \mathrm{bar}^{-1} @ 20^{\circ} \mathrm{C}$.

Fig.4. Variation of the residual resistance with the filtered volume at each latex filtration cycle for two different permeate fluxes. Error bars correspond to the variations observed for the different cycles in the same test.

Fig.5. Variation of the residual resistance with the filtered volume at each clays filtration cycle for two different permeate fluxes. Error bars correspond to the variations observed for the different cycles in the same test.

Fig.6. Critical Filtered Volume versus operating flux and suspension.

Fig.7. Variation of $\Pi_{m}$ (where $\Pi_{m}=\Delta \mathrm{P}-\Delta \mathrm{P}_{0}$ based on eq. 4 ) versus the volume $V$ for constant flux operation. Interpretation with a critical osmotic pressure $\Pi_{c r i t}$ and a residual resistance $R_{\text {res. }}$ 
Fig.8. Schematic of experimental filtration/rinse cycle (latex $-J=1101 \mathrm{~h}^{-1} \mathrm{~m}^{-2}-V f=841 \mathrm{~m}^{-}$ ${ }^{2}$ ) by dissociating the contribution of osmotic pressure and cake resistance.

Fig.9. Residual resistance versus filtered volume. Fouling lag (and its associated $C F V$ and $\left.\Pi_{\text {crit }}\right)$ appears to be a means to characterise fouling, being complementary to the classic determination of cake specific resistance, $\alpha$.

Fig.10. Chart for determining the optimized working zone: squares represent the latex suspension, triangles represent the clay suspension - dashed curves represent the extrapolation when considering $J^{*} C F V$ constant. 


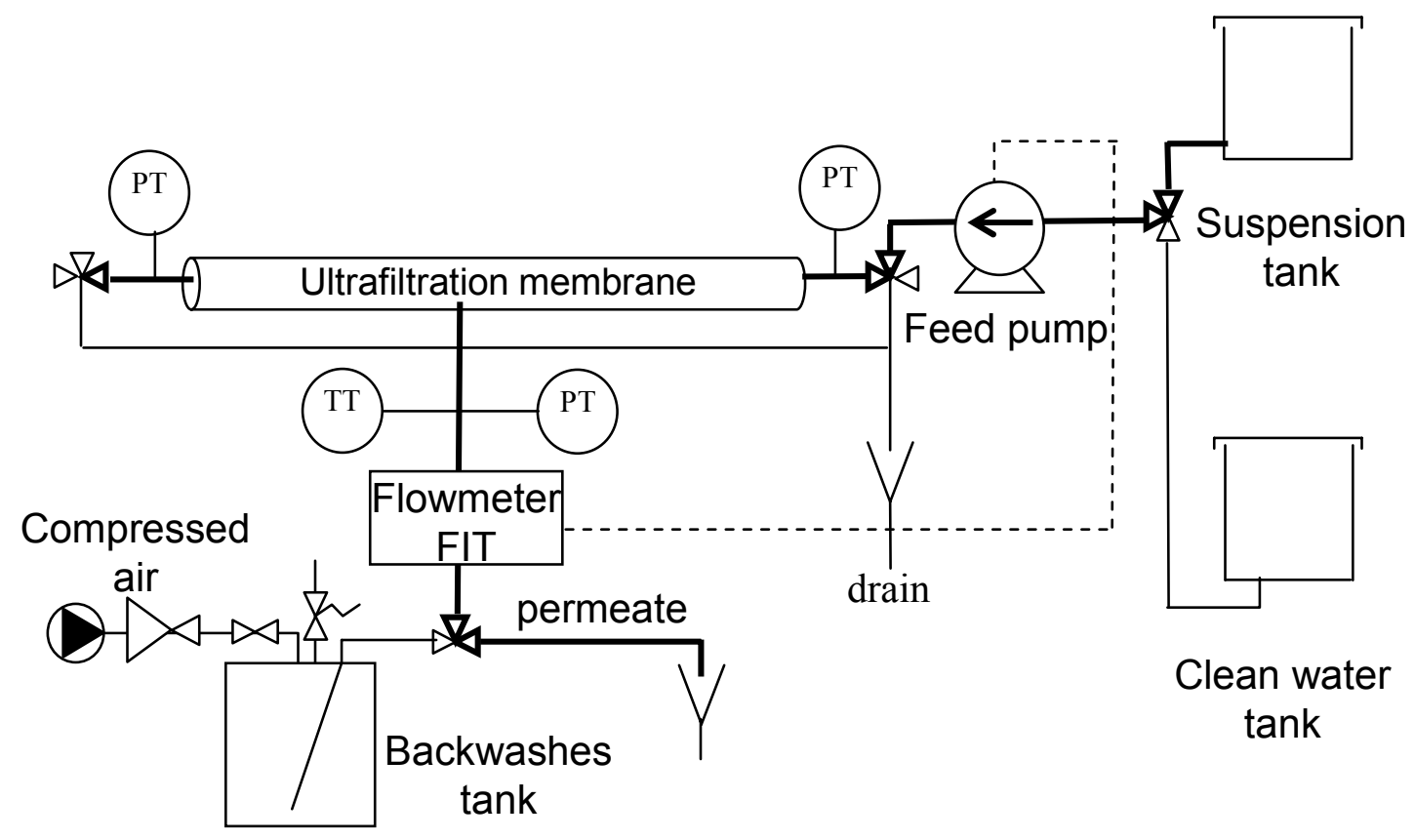

Figure 1 


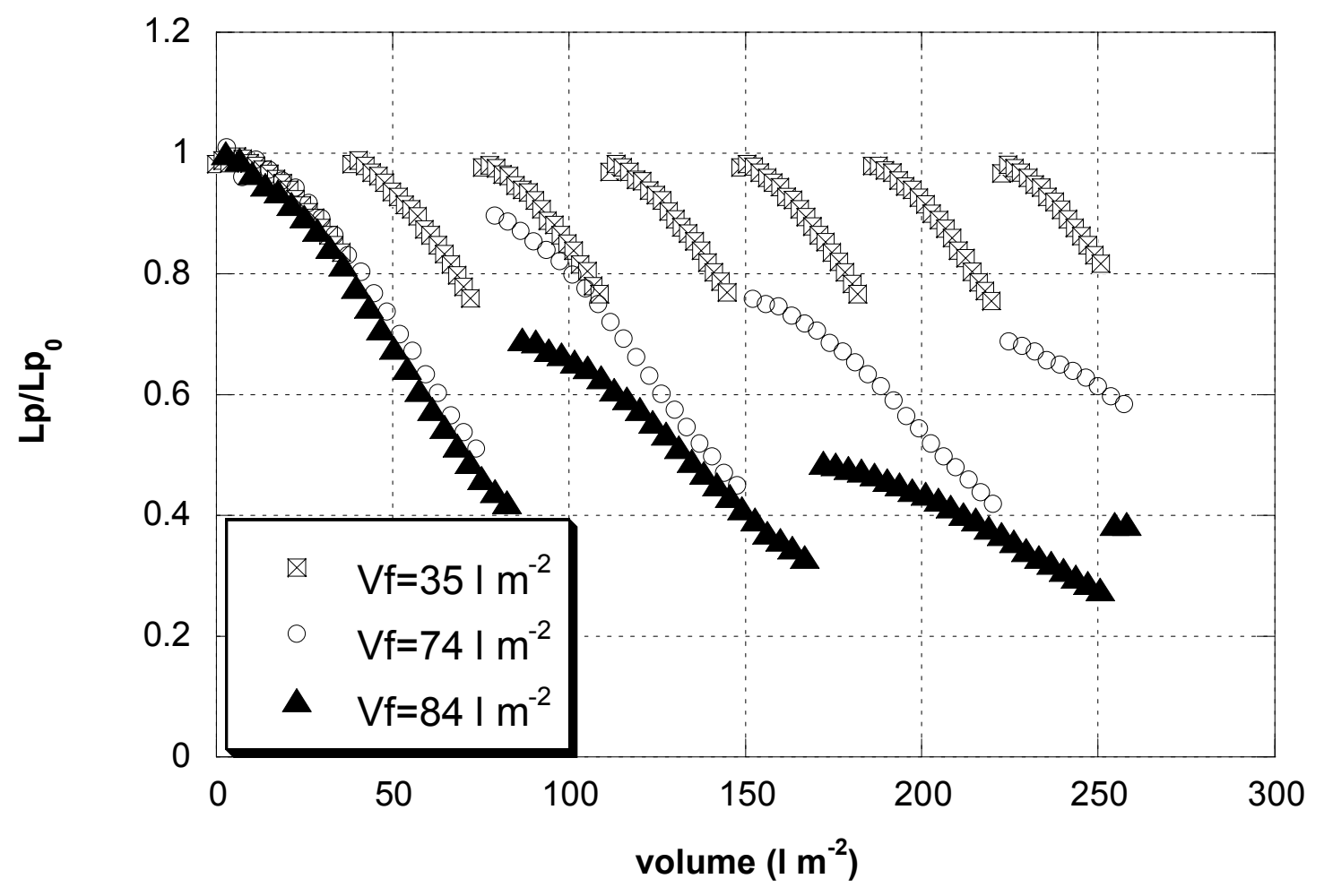

Figure 2 


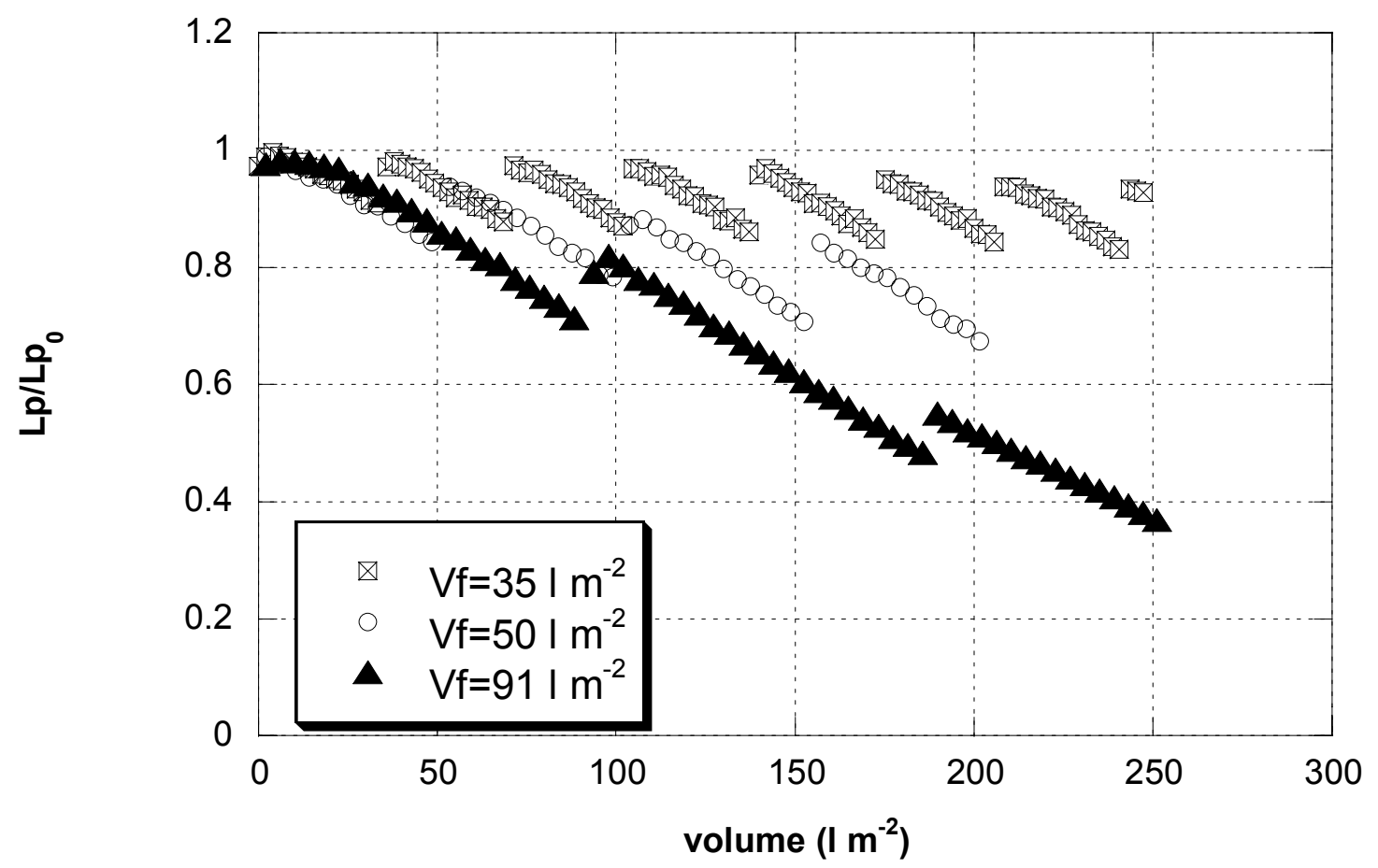

Figure 3 


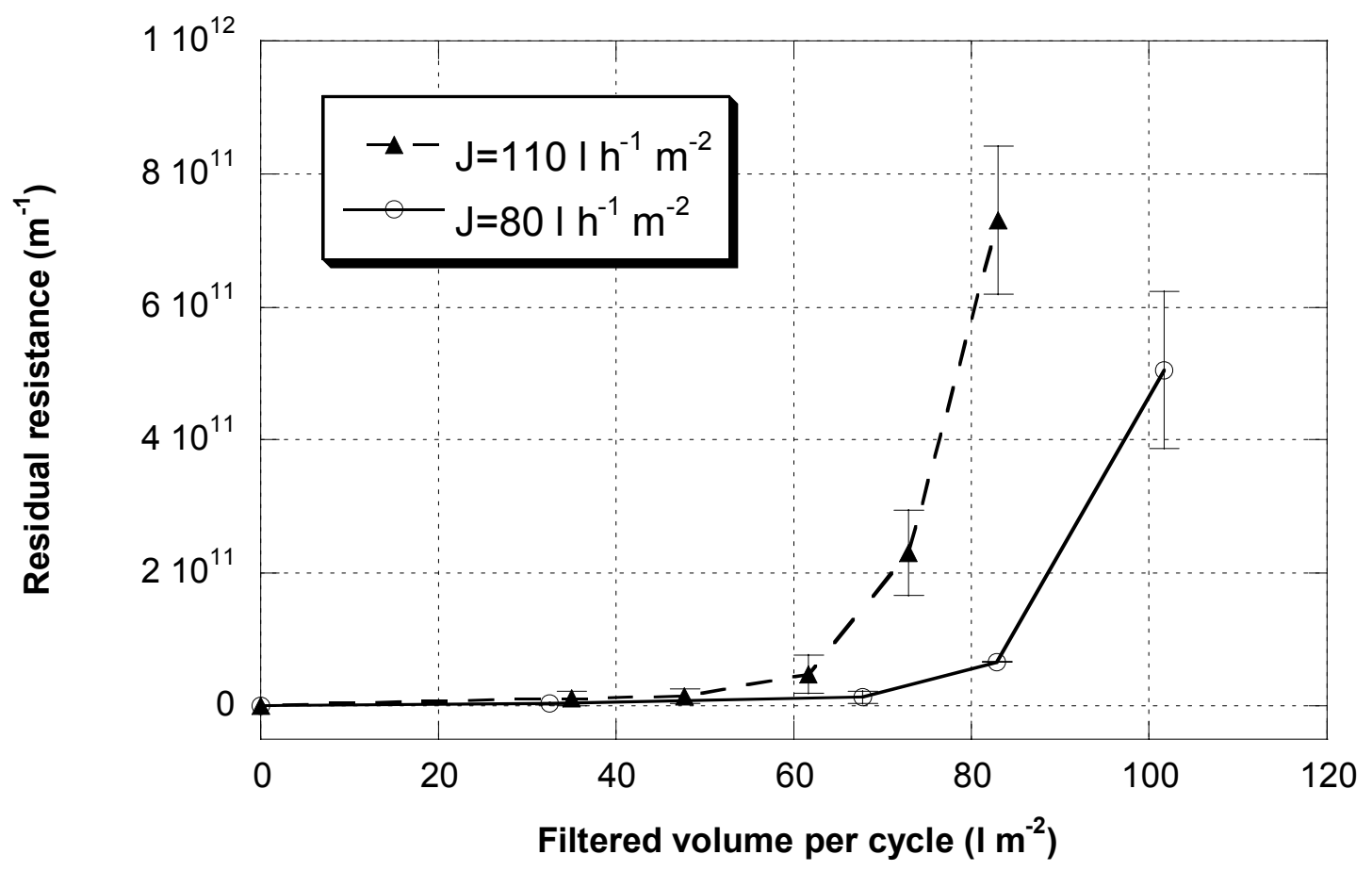

Figure 4 


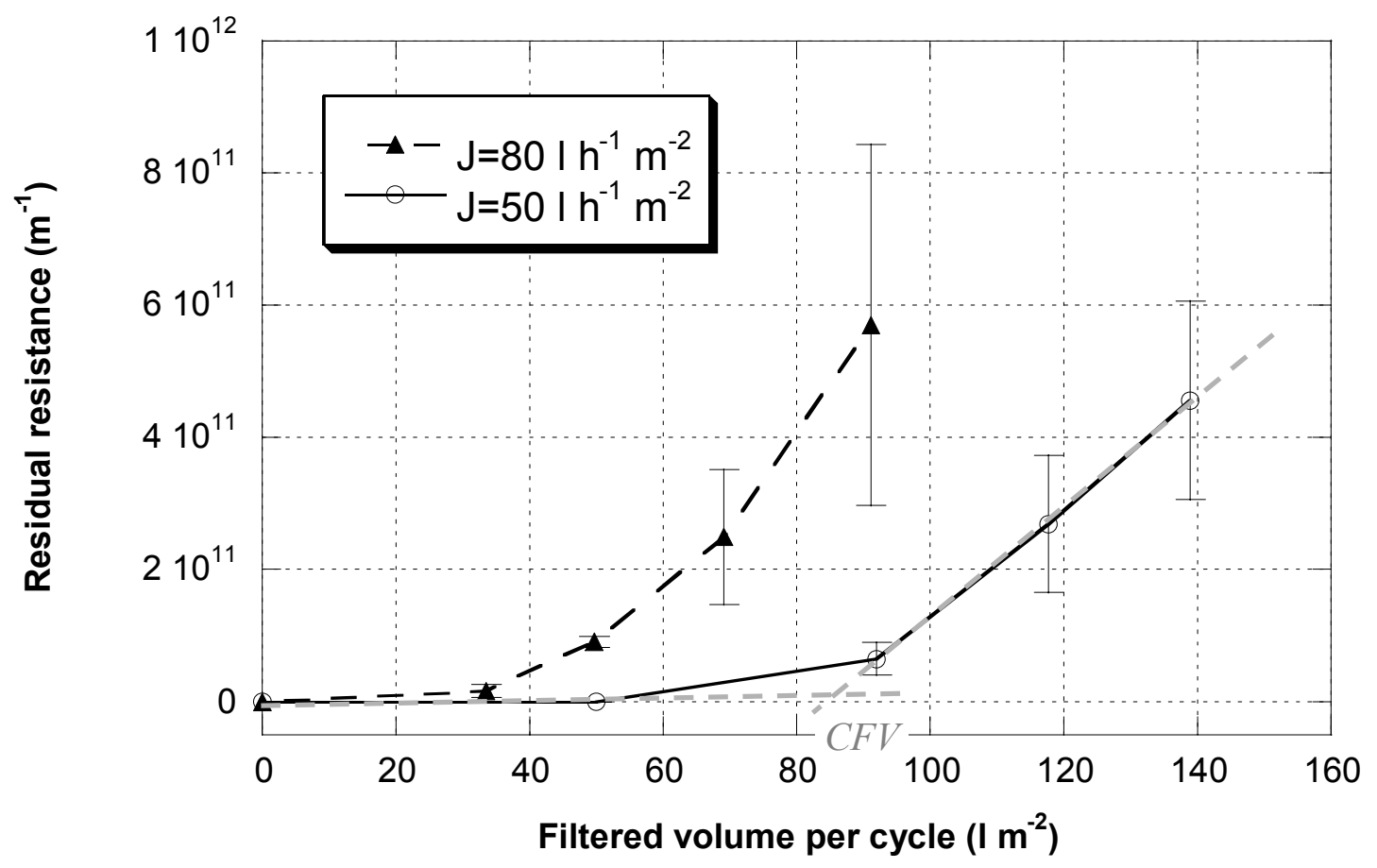

Figure 5 


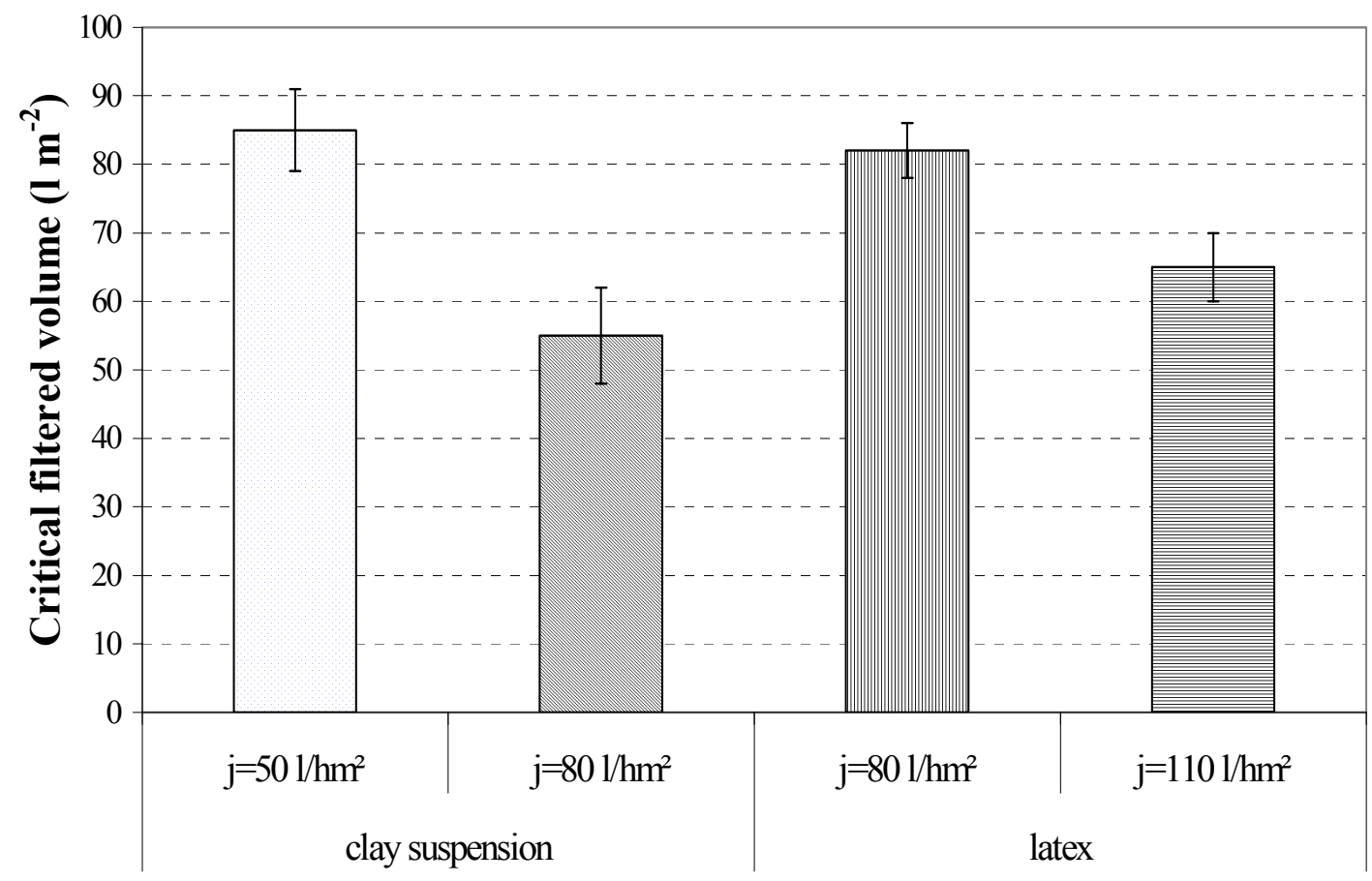

Figure 6 


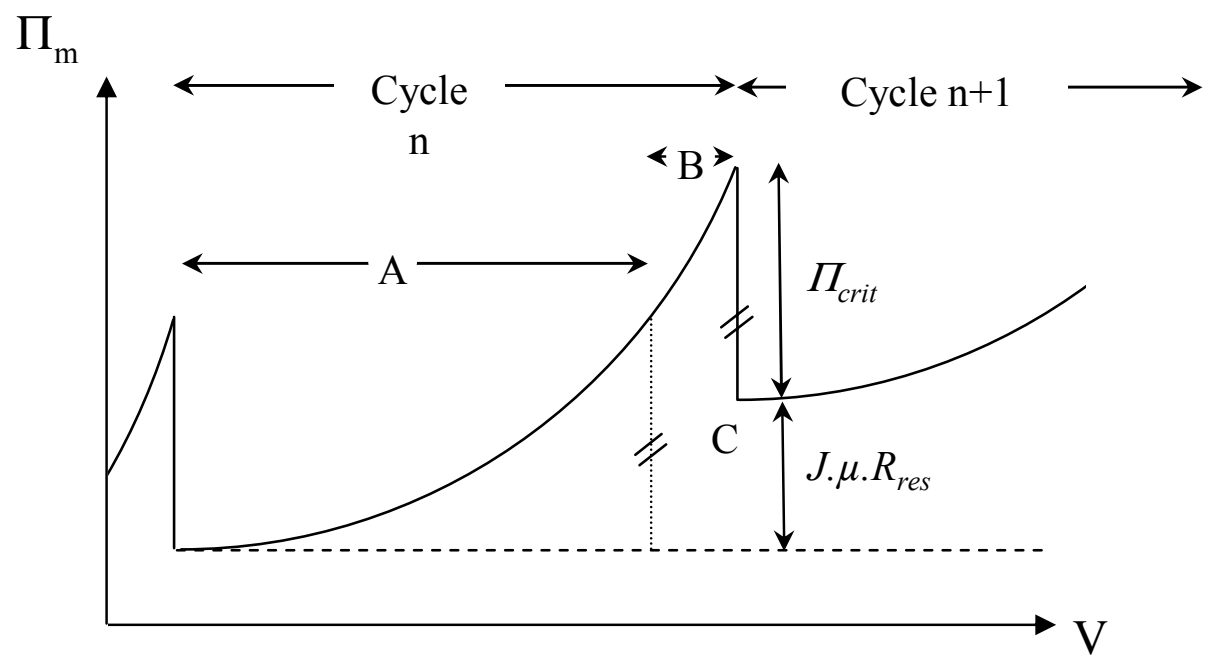

Figure 7 

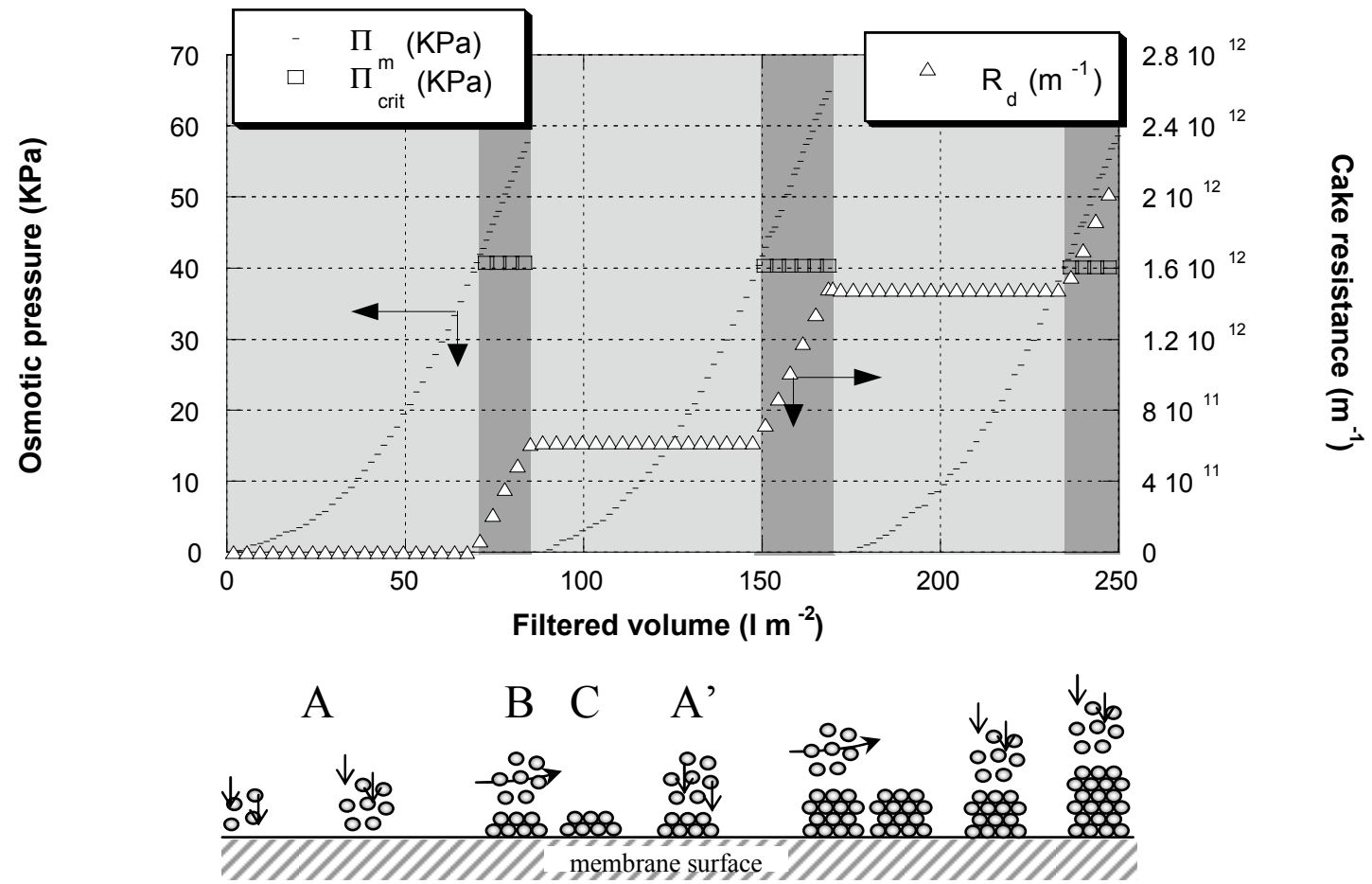

Figure 8 


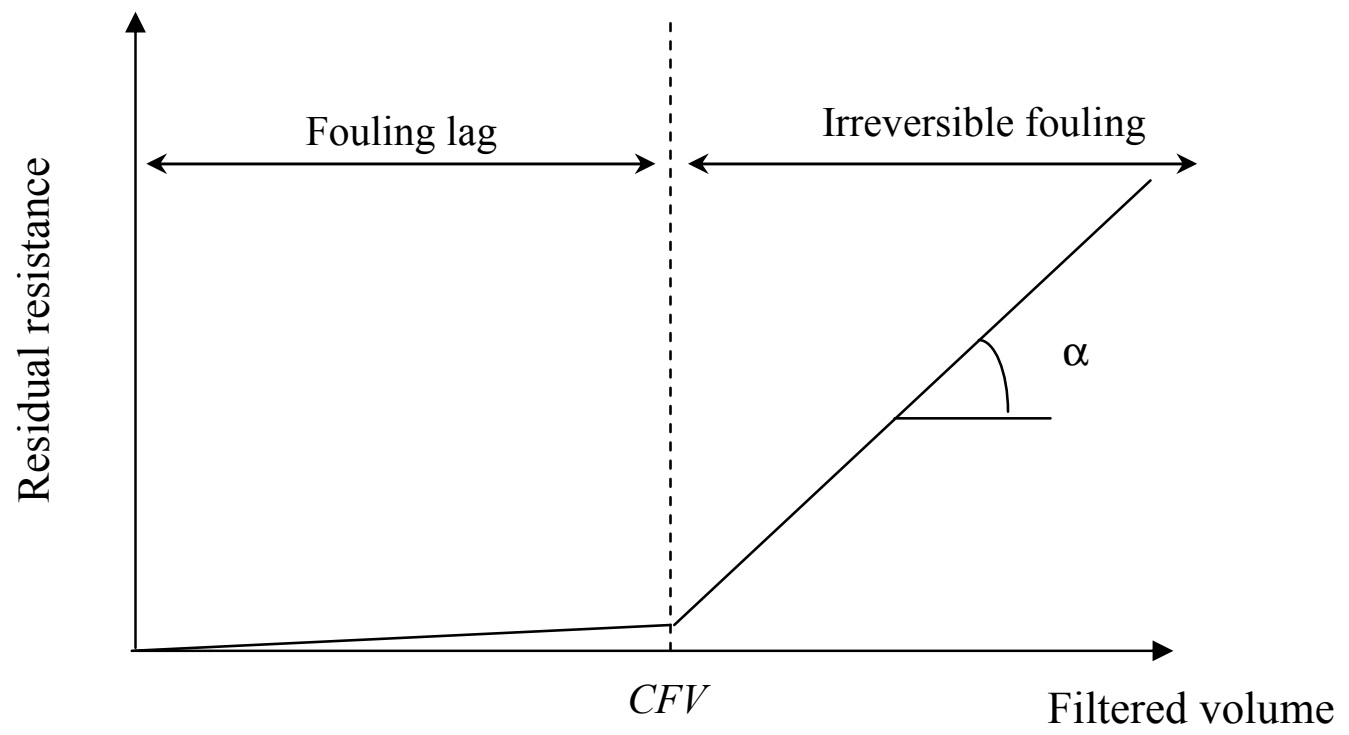

Figure 9 


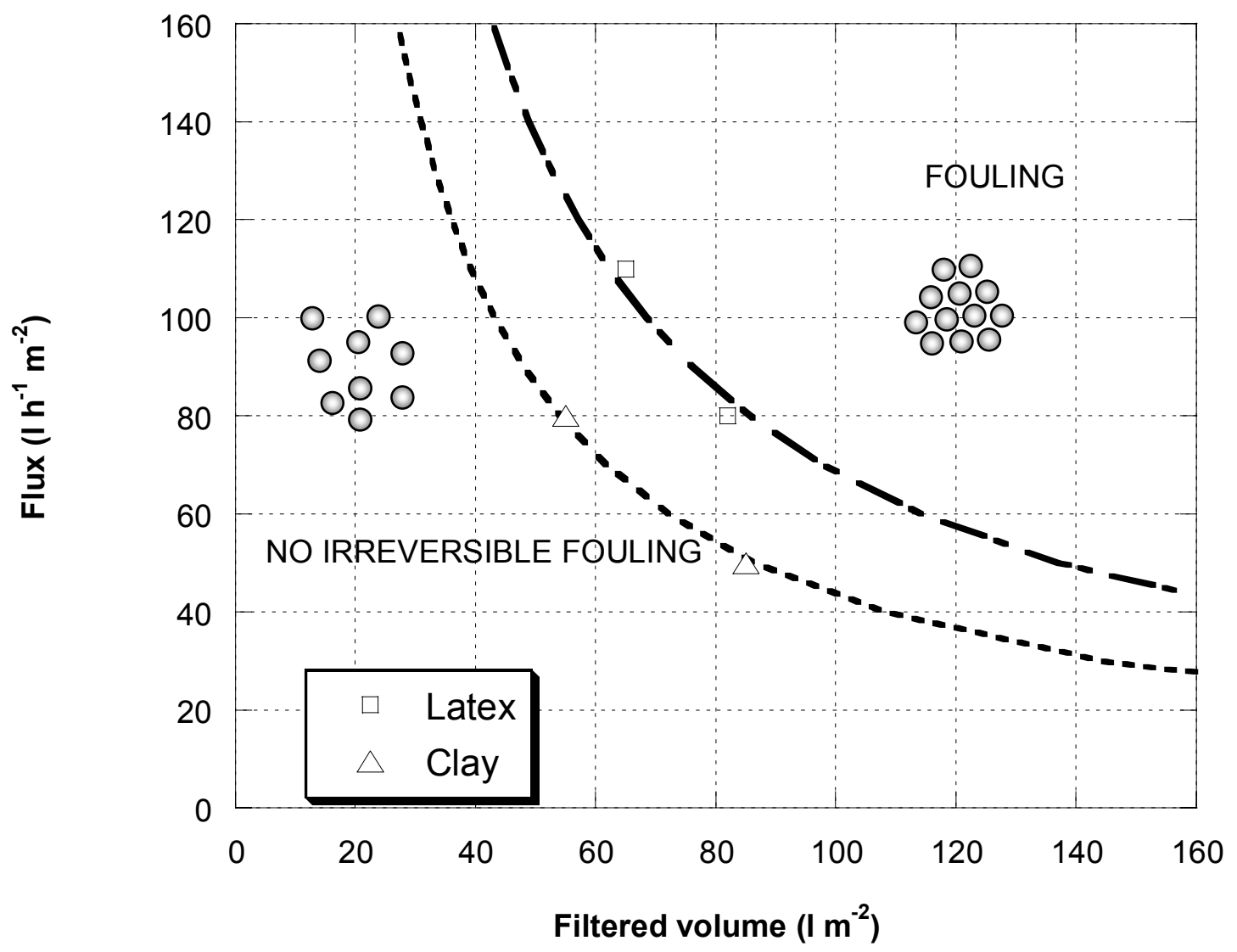

Figure 10 